\title{
Ciberespaço: conceito à procura de um nome*
}

\section{RESUMO}

Este ensaio estuda as características teóricas, pragmáticas e cognitivas do ciberespaço, relacionando-as com aquelas que constituem os paradigmas de análise e interpretação empregados no território científico da comunicação. Essas questões são recursivas em textos de vários autores que se ocupam do ciberespaço, mas em todos, observa-se que aquelas definições surgem como obstáculos que se manifestam nos eufemismos dos nomes atribuídos ao ciberespaço. Entende-se, por hipótese, que a utilização daquele recurso está diretamente relacionada à necessidade de produzir/descobrir novos paradigmas para nomear e definir as características cognitivas produzidas e/ ou estimuladas pelo cotidiano presidido por um ciberespaço.

\section{PALAVRAS-CHAVE}

ciberespaço

comunicação

ciência

\section{ABSTRACT}

This paper will try to show theoretical, pragmatics and cognitive cyberspace characteristics in relation to communication analysis and interpretation paradigms. These questions are frequent to cyberspace authors but in everyone we observe these cognitive definitions named by euphemisms or metaphors. By hypothesis, we understand this use is linked to the necessity to invent new paradigms to define or to name cognitive characteristics produced or stimulated by daily cyberspace.

\section{KEY WORDS}

cyberspace

communication

science

\section{A procura de um nome}

"El jardin de senderos que se bifurcan" es una enorme adivinanza, o parábola, cuyo tema es el tiempo; esa causa recóndita le prohibe la mención de su nombre. Omitir siempre una palabra, recurrir a metáforas ineptas y a perífrases evidentes, es quizà el modo màs enfático de indicarla" (Borges. Ficciones, p. 99).

Ciberespaço: conceito à procura de um nome

Cibercultura de um espaço ciber

Ciberespaço como máquina de guerra

Nomear o ciberespaço

Cibercultura do ciberespaço

A hesitação e a procura de um nome adequado para esse trabalho é um índice da sua natureza. O nomear é um ato cognitivo.

Sem dúvida, não se pode desconhecer que a fundamental tarefa epistemológica concentra-se na elaboração de um conceito e sua conseqüente síntese, entretanto, esse objetivo só se dá a conhecer através de uma forma que, superando todas as características miméticas do fenômeno, permite que o conheçamos ou o identifiquemos pelos nomes que o sintetizam. Ou seja, o ato de nomear tende a superar toda relação arbitrária entre um significante em remissão para um significado.

Além disso, em ciência, um nome não simplesmente designa, mas pode configurar uma imagem que, em mediação, pode sugerir inferêncais imponderáveis ou surpreendentes. Ou seja, o nome de um conceito vai muito além da simples designação, porque não é unívoco mas, dentro de uma aproximação lógica ambigua, pode oferecer sínteses dúbias que Flusser identifica como nomes secundários que vão além dos nomes próprios:

Podemos ampliar a nossa concepção do intelecto da seguinte maneira: é ele o campo no qual ocorrem palavras de dois tipos, nomes próprios e palavras secundárias... Podemos distinguir duas tendências dentro do campo do intelecto, uma centrípeta e outra centrífuga. A força centrífuga é a "intuição poética" enquanto que a força centrípeta é a " conversação crítica". O resultado da "intuição poética" são os nomes próprios, o resultado da "conversação crítica" é a transformação desses nomes em palavras secundárias, ou a sua eliminação do campo do intelecto. Se o intelecto é o campo da dúvida, devemos dizer que a dúvida tem duas tendências: a "intuitiva" que expande o campo da dúvida, e a "crítica", que o consolida (Flusser, 1999, p. 65,66).

Porém, nos dois casos, temos atos cognitivos que se fazem móveis, dinâmicos e incompletos através da críti- 
ca epistemológica que expande o conceito para além do nome, revelando-lhe novas dimensões. Nesse trabalho, nos ocuparemos das nomeações do ciberespaço que, enquanto crítica e palavras expandidas, configuram as representações epistemológicas que têm sido desenvolvidas no território daqueles estudos comunicativos ou próximos a ele.

\section{0 ciberespaço como quase ciência}

No longinguo 1965, Umberto Eco publicou uma obra onde propunha dois nomes gerais e polêmicos: apocalípticos e integrados. Com esses nomes, procurava-se criar duas sínteses das categorias receptivas da cultura de massa. Atualmente, essas duas sínteses estão ultrapassadas porque se referem à obviedade de reações díspares, ante a surpresa de toda revolução cultural ou científica que impõe o reconhecimento da violação de expectativas já alicerçadas, consolidadas, conforme Thomas Khun apresentou em obra fundamental, onde analisa o quadro de mudança de paradigmas como eixo da revolução científica. Nesse quadro de mudanças, a cultura de massa foi violada pela cibercultura que a reduziu ao plano normal e corriqueiro dos sistemas de comunicação lineares e industrializados.

\section{Para a crítica epistemológica, parece urgente inibir a ameaça da impossibilidade comunicativa que, iniciada com a comunicação de massa, estaria, com o digital, prestes a desaparecer do plano humano para instalar-se além, no pós-humano apocalíptico.}

Entretanto, apocalípticos e integrados são nomes que parecem corresponder e são freqüentemente lembrados para designar a realidade atual vinculada à emergência da cibercultura e encontrada no ciberespaço, como decorrência da Internet, entendida como meio comunicativo matriz da qual decorrem redes, blogs, chats, fotologs, sites, e os novos dispositivos móveis. Todos esses nomes constituem meios comunicativos com distintas atuações, mas eclodem no e a partir daquele espaço.

O prefixo "ciber" que atua como predicativo do espaço e da cultura que decorrem do suporte digital não os distingue com clareza no sentido de indiciar hierarquia, ou sobretudo, relações entre eles. Entretanto, ambos e, sobretudo a cibercultura, parecem ser credores de um capital cognitivo que transforma a tecnologia digital em um meio comunicativo que promove interfaces, interatividades e longínquas e duvidosas, porém possíveis, inclusões sociais, políticas e culturais.

Entretanto, o prestígio e atualidade dos conceitos introduzidos por Eco parecem justificar-se pela díspar profusão de nomes com os quais se pretende designar ou identificar os meios comunicativos que decorrem da tecnologia digital e que, não raro, são confundidos como suas faces homólogas. Entretanto aqueles nomes apontam para sínteses distintas, embora essa distinção seja estranha e difícil.

Essa dificuldade aponta, não só para o caráter revolucionário implícito na realidade epistemológica introduzida pela emergência da tecnologia digital, mas, sobretudo, para seu caráter de processo e passagem entre o conhecido e o novo e sua consequente fase de relação cognitiva que constitui toda ciência quando se apresenta como saturação das anteriores operações epistemológicas, mas não evidencia, com clareza, suas novas estruturas. Entretanto, no caso "ciber" esse processo relacional está longe de ser esgotado, o que significa que aquela saturação se mostra hesitante e em constante processo de revisão, daí decorre a dificuldade da sua nomeação e a consequente profusão de nomes que inspira.

\section{Os nomes para um nome}

Aquela profusão de nomes indica a obstinada tentativa de compreender e ordenar o território da comunicação presidida pela tecnologia digital e, sobretudo, pelos meios comunicativos que dela decorrem. Porém, se um nome ordena e identifica, sua profusão parece traduzir uma ameaça, porque foge da linearidade que constitui controle e administração de uma área científica. Para a crítica epistemológica, parece urgente inibir a ameaça da impossibilidade comunicativa que, iniciada com a comunicação de massa, estaria, com o digital, prestes a desaparecer do plano humano para instalar-se além, no pós-humano apocalíptico. A recolta, certamente parcial, dos nomes ou modos de identificar o ciberespaço aponta para uma negação afirmativa, para uma oposição, ou melhor, para uma adaptação evolutiva.

Negroponte, 1995

A vida digital: título da obra

Diversão da pesada, 187

Mídia para vestir, 199

Persona digital, 206

Superestrada da informação, 191

Dentro e fora do país ao mesmo tempo, 184

Hillis, 2003

Sensações digitais: titulo da obra

Fronteira eletrônica, 265

Gates, 1996 


\section{Rheingold, 1996}

A comunidade virtual: título da obra

\section{Kerckove, 1997}

Metáfora tátil, 79

Mão da mente, 80

Consciência simultânea partilhada, 82

Homo participans, 86

\section{Levy}

Inteligência coletiva .1999, 29

Virtualização como êxodo .1996, 19

Dialética do possível .1996, 59

Tecnologias da Inteligência.1993: título da obra

Trívio antropológico dos signos, das coisas, dos seres. 1996, 81

Ciberespaço: virtualização do computador. 1996, 46

Trivinho, 2007

Sóciosemiose plena da interatividade, 122

Manovich, 2006

Espacialização da experiência, 321

Poética da navegação, 328

$\mathrm{Ou}$

Tapias, 2006

Internautas e Náufragos: título da obra

Máquina de Modernidade, 14

Nova cidade de Deus, 16

\section{Baudrillard}

A Ilusão vital . 2001: título da obra

Espaço além do fim .2001, 41

Acontecimento sem lugar .2001, 44

Relógio sem ponteiro. 2001, 44

Milenarismo sem amanhã. 2001, 40

Realidade virtual do apocalipse .2001, 42

Comédia póstuma do apocalipse .2001, 42

Espaço além do fim .2001, 43

Neurose coletiva .2001, 46

Liquidação do fim do século .2001, 47

Fim interminável .2001, 49

História anoréxica. 2001, 49

Fim do cenário da política, do social,da história ,2001, 50

História retrospectiva ou necrospectiva.2001, 55

Assassinato do real. 2001, 65

Assassinato do signo.2001, 61

Clonagem além do humano. 2001, 7

Hiper-real .2008, 22

Tempo real .2008, 127

Pacto de lucidez .2008: título da obra

Inteligência do mal .2008: título da obra

Realidade integral .2008, 12

Inferno do poder. 2008, 115
Trivinho, 2007

Bunkerização da vida, 39

Prótese invisível do inconsciente, 295

Signo vazio, 129

Dromoinaptidão cibercultural, 222

\section{Virílio}

Organização pré-geométrica do espaço .1993, 22

Hiperespaço sem dimensão. 1993, 92

A dimensão perdida .1993, 81

A cidade superexposta .1993, 7

A fratura morfológica.1993, 22

Acidente original .2005: título da obra

A máquina de visão. 1988, título da obra

Estratégia da decepção .1999, título da obra

A política do pior .2000: título da obra

A análise sugerida pela simples leitura desses nomes ordenados comparativamente nos leva a distintas observações. Se refletirmos não sobre os nomes ou sobre as formas de nomear tomados unitariamente que, parece, não levariam a conclusões mais amplas, mas se considerarmos, ao contrário, o conjunto de nomes, veremos que o ciberespaço ou a cibercultura aparecem em uma simultaneidade nomeativa ou seja, ao mesmo tempo positiva e negativa, plurinominável e inominável, ambivalente sem ser ambigua visto que se presta a conceituações díspares, fluídas que definem pela indefinição: aforismas à maneira de Heráclito reeditado na pós-modernidade e mais atual do que o próprio digital visto que opera sobre sua essência:

Coisas tomadas juntas são todos e não-todos, algo que é trazido junto e trazido em separado; que é consoante e dissonante; fora de todas as coisas temse a unidade e fora da unidade, todas as coisas (Heráclito, apud Collinson, 2004, p. 22)

Nesse sentido, e considerando o caráter objetivo e seguro dos nomes "apocalípticos e integrados", observa-se que, se aqueles nomes caracterizavam uma oposição entre favoráveis e desfavoráveis à comunicação de massa, entendida como ameaça ou novidade, somos obrigados a inferir que a nomeação de Eco é frágil ante a necessidade de nomear o digital. Ou seja, se apocalípticos e integrados são nomes que identificam dois blocos em antítese, aquela profusão de nomes que procuram flagrar as inusitadas dimensões dos meios comunicativos que decorrem do digital se apresentam como complexidades que não se deixam sintetizar. Entretanto, aquela nomeação é imprescindível para que seja possível sintetizar o novo paradigma que, complexo, exige ser nomeado a fim de ser possível catalogá-lo no território crítico-científico e dar-lhe um lugar epistemológico passível de identificação. Ou seja, mais do que o nome como substantivo, é necessária a ação do nomear. 


\section{0 nomear}

Explicitando ou não, um interesse epistemológico, é notável a atenção conferida por numerosos, distintos e conhecidos cientistas à necessidade e ao interesse do nomear. Para citar alguns ilustres e sem esgotar a lista que os coleciona, impõe-se lembrar os nomes de Foucault (capítulos 4 e 5, em As Palavras e as Coisas); Flusser ("Do Nome", em A Dúvida); Derrida ("A estrutura, o signo e o jogo", em A Escritura e a Diferença,) e ("A guerra dos nomes próprios" e "A ciência e o nome do homem", em Da Gramatologia; Lotman e Uspenski ("Mito, nome e cultura", em La Semiosfera III); Kuhn ("A metáfora na ciência" e "Comensurabilidade, comparabilidade, comunicabilidade", em O Caminho desde a Estrutura); Rossi ("Ordem e desordem no mundo", em A Ciência e a Filosofia dos Modernos); Bauman ("A busca da ordem", em Modernidade e Ambivalência); Maffesoli ("A metáfora", em Elogio da Razão Sensível).

O nomear é um ato cognitivo radical e procura ordenar, separar, classificar, segregar a fim de conter o horizonte caótico da idéia. Desse modo, o nome adere ao fixo e ao estável, na própria medida em que repele o fluxo e o indeterminado:

Sem dúvida o centro de uma estrutura orienta e organiza a coerência do sistema e lhe permite o jogo dos elementos no interior da forma total. Além disso, atualmente, uma estrutura privada de todo centro representa o próprio impensável (Derrida, 1967, p. 409).

Verifica-se, com Derrida, que para superar o caótico é necessária a centralização estrutural do conceito e a clara e visível dimensão do referente nomeado a fim de que seja possível conter a rarefação da idéia e submete-la à unidade, à integridade e à segurança dos seus limites. Nesse sentido, o nomear exige fixidez para ordenar o conjunto através da tradução de um nome capaz de iluminar o que lhe é próprio e eliminar o que lhe é estranho. Portanto, o nomear exige a fixidez que repele as interpretações:

Também não se trata de uma racionalidade mais geral que imporia formas idênticas à reflexão sobre a gramática e à taxinomia. Mas sim de uma disposição fundamental do saber que ordena o conhecimento dos seres segundo a possibilidade de representa-los num sistema de nomes ( Foucault, 1987, p.173).

Portanto, um nome é, antes de tudo, uma identificação que confere sentido porque dele se depreende os limites de um lugar epistemológico que, como se sabe, sempre supõe a centralidade de um corpo conceitual e confere estrutura a um campo de conhecimento, garantindo a indispensável autonomia de uma área científica que, com ele, se consolida.

Porém, se observarmos os nomes conferidos ao espaço ciber no calor da urgência do nomear para ordenar a ameaça daquilo que escapa ao controle, observamos que seus agentes diferenciais são, sobretudo, metafóricos. Ou seja, recuperam de modo aproximativo a possível referência subjacente àqueles nomes alternativos e não exclusivos. Portanto, essa fragilidade colocaria em questão a tentativa de considerar as decorrências da tecnologia digital como uma área de conhecimento e essa limitação abre outros elementos que devem ser considerados.

\section{0 que importa é descentrar aqueles pseudo-nomes ou modos de nomear a fim de descobrir-lhes, no caráter metafórico, os sentidos subjacentes e encontrar o que neles se encontra escondido ou desviado.}

A referência a que um nome implica não pode ser dúbia ou frágil pois, se assim for, a relação entre o fenômeno estudado e o nome que a ele se aplica perde o sentido. Se observarmos que tempo real e realidade integral são conceitos-chave da existência que decorre da tecnologia digital, veremos que parece absolutamente inócuo pensar ou falar em uma possível Teoria Causal da Referência, como parâmetro científico ao qual o nome deveria referir-se ou conter e descrever. Ou seja, sem referente, o espaço ciber tem uma realidade integral esgotada na ausência de tempo do tempo real, o que o faz auto-referente e sem limites históricos ou geográficos:

Pareceria que a evolução (ou a involução) para um universo integral é irresistível. Mas ao mesmo tempo, pareceria que a forma dual é indestrutível. Nada permite especular sobre o desenlace deste duplo movimento contraditório. Assistimos à confrontação insolúvel entre uma forma dual e uma integração total.

Mas esta última só o é em aparência, visto que sempre está presa à desintegração secreta de um dissenso que a trabalha por dentro. Se trata da violencia mundial imanente ao sistema-mundo e que lhe opõe, internamente, a forma simbólica mais pura do desafio... Pulsão integral e pulsão total: aqui está o Grande Jogo ( Baudrillard, 2008, p. 16).

Como se vê, ao debruçar-se sobre a necessidade de conferir um referente que centralizaria a realidade inte- 
gral, entendida como síntese do conhecimento contemporâneo que decorre do digital, Baudrillard cede à evidência contraditória entre o nome e sua possível referência inócua, descentralizada.

Porém, Kuhn, dentro da característica que lhe é peculiar e o tornou notário no campo das revoluções científicas, não adere àquela contradição, mas procura abolir o espectro de uma Teoria da Referência, como elemento indispensável à estruturalidade cognitiva de um nome e observa que, em ciência, a semiose de uma referência torna-se cada vez mais rarefeita e imprecisa:

A teoria causal da referência corta o nó górdio ao negar que os nomes próprios tenham definições ou sejam, de alguma maneira, associados a descrições definidas (Kuhn, 2006, pp. $243 / 244)$.

Contra a senha de um nome surgiria a possibilidade heurística de algo que, sem ser nome ou ser apenas difuso, apontaria para uma designação paralela que, ao contrário, nomearia de modo apenas possível e metafórico que designaria um referente desenhado por similaridades:

Acrescento que, a bem da brevidade, ignorarei doravante a distinção que já salientei entre a metáfora propriamente dita e processos semelhantes a metáforas. Nessas observações finais, "metáfora" se refere a todos aqueles processos nos quais a justaposição, seja de termos, seja de exemplos concretos,origina uma rede de similaridades que ajuda a determinar o modo como a linguagem se liga ao mundo (Kuhn, 2006, p. 249).

Essa imprecisão apontaria, portanto, para algo aproximativo que substituiria o nome pela metáfora e apontaria para algo paralelo que, ao contrário do nome, esvaziaria o sentido, a semiose plena, e criaria uma indeterminação tão mais radical, quanto mais analógicos e comparativos fossem os recursos verbais utilizados para metaforizar ou recuperar, de modo aproximado, a possível referência. A metáfora passa a atuar como "acesso epistêmico" e, no caso do ciberespaço ou da sua consequência, a cibercultura, passa a figurar como verdadeira "senha de acesso epistêmico". Ou seja, se eufóricos ou disfóricos, reconhece-se que se procura sintetizar os nomes através de similaridades que, positivas ou negativas, projetam uma avaliação que, a despeito da ausência de um referente causal ou operacional, acaba por criar um outro, não só imaginário, mas sobretudo, avaliativo, qualificativo.

Desse modo, tempo virtual, realidade integral, espaço crítico, inteligência do mal, política do pior, estrada do futuro, ou todos os demais nomes elencados constituiriam, embora herméticos, imprecisos e metafóricos formas de nomear de modo oblíquo e ambivalente aquilo que não se nomeia, porque resiste ao controle do nome, mas sobre o que se ousa falar, escrever e, sobretudo, usar de modo entusiasmado e eufórico no limite da promessa de um futuro melhor ou revoltado e nostálgico, ante um mundo sem fronteiras definidas.

Aqui está a questão, atrás daqueles nomes metafóricos repousa a arqueologia do espaço e da cultura ciber. O que importa é descentrar aqueles pseudo-nomes ou modos de nomear a fim de descobrir-lhes, no caráter metafórico, os sentidos subjacentes e encontrar o que neles se encontra escondido ou desviado. Ou seja, é necessário procurar aquilo que, escondido na metáfora, contém a estruturalidade da epistemologia do novo conhecimento ciber ou aquilo que se situa na contra-referencialidade de um nome único ou na história de uma polissemia que estende ao infinito o jogo da nomeação e dos seus significados.

Desse modo, aquela profusão de metáforas que substituem nomes, se transformam em capital cognitivo e escondem duas tendências básicas ao espaço e à cultura ciber: são, ao mesmo tempo, positivos e negativos. Entretanto não há , entre elas, oposição, embora pareçam negarem-se ou colidirem.

Entre os nomes disfóricos parece prevalecer, de um lado, a tentativa de traduzir o desconhecido e ameaçador fenômeno ciber naquilo que se conhece desde o movimento modernista, culminou no desastre e nas consequências de duas grandes guerras e constitui ameaça social e política constante e insuperável.

De outro lado, entre os eufóricos, encontram-se outros dois caminhos não totalizantes ou divergentes: em primeiro lugar, o entusiasmo da descoberta de um novo instrumental comunicativo, uma nova e inteligente mediação destinada a superar as antigas tecnologias lineares de massa, embora e possivelmente, possa resultar no mesmo efeito manipulativo centrado no consumo e na alienação que delas decorreu, em segundo lugar, surge a tendência curiosa voltada para o futuro, que procura envidar esforços e imaginação para prever os resultados cognitivos e sociais possíveis e subjacentes à nova tecnologia e aos seus meios comunicativos.

Entre os dois casos, positivos ou negativos, é possível apreender a tentativa de estabelecer sínteses que lembrariam, ora a nostalgia do passado que era melhor porque dele já se conhecia todas as ameaças, ora a euforia contida na possibilidade de mudar radicalmente o quadro cultural de uma modernidade fracassada que, sob a égide do capital sempre presente, mas à sua revelia, poderia alterar o quadro criativo, social, político e econômico da desigualdade planetária.

Portanto, os dois lados não se opõem necessariamente, embora ideologicamente divididos, apresentem-se em oposição e divergência. Ou seja, nos dois casos, observase o pensamento que se volta para o resgate da segurança e da certeza cognitivas que decorrem da linearidade estabelecida entre causas que pré-determinam seus efeitos utilizando ou não instrumentos tecnológicos. Para a 
comunicação aqueles efeitos predeterminados não têm sentido, porque se distinguem das consequências de meios que geram um ambiente comunicativo novo, mas imprevisto, visto que entre suporte tecnológico e meio comunicativo não há mútua implicação ou qualquer relação causal.

\section{A cibercultura do espaço-ciber}

Se o espaço ciber é o locativo da cibercultura, ela é consequência da aceleração que o mobiliza. Desse modo, torna-se quase impossível a empiria e o conhecimento porque, móvel e inconstante, aquele espaço não se recusa ao conhecimento, mas é indeterminado, movente, sem ser vazio. Ao contrário, os nomes gerados na confluência entre espaço e cultura "ciber" e, sobretudo, na oposição que, entre eles, se estabelece, parecem impor a necessidade de fixar um objeto científico que, ao contrário, se caracterizaria pela instigante indeterminação e fragilidade de limites.

Aquele nomear parace querer resgatar, nos dois casos, um paradigma científico que, em segurança, poderia dar conta do fenômeno comunicativo que decorre das novas tecnologias.

Na confluência entre espaço e cultura "ciber", impõese estatizar um objeto científico que se caracteriza pela indeterminação e fragilidade de limites, mas, exatamente por isso, instigante. Porém, na tentativa de superar a opacidade de um objeto científico indeterminado, a ciência que se estabelece pelas sínteses científicas geradas pela cibercultura e pelo espaço ciber parecem requerer, ao mesmo tempo, tanto a nostalgia do conhecido que, embora nefasto, já se apresenta nomeado e classificado, como a operativa atividade instrumental do fazer ou da possível previsão de uma revolução social que poderá gerar.

Ao contrário e visto que indeterminado, aquele objeto só se deixa vislumbrar com alguma clareza de síntese se for apreendido nos seus desvios positivos ou negativos, como sugere Morin:

A história da nossa terra é acidental, e através desses acidentes houve a extraordinária proliferação de formas vegetais e animais, das quais, de um ramo de um ramo de um ramo... da evolução animal surgiu o ser humano e, finalmente, a consciência humana... Somos, portanto, um produto "desviado" da história de mundo; isto nos permite compreender que a evolução não é qualquer coisa que avança formalmente, majestosamente, como um rio, mas parte sempre de um "desvio" que começa e consegue impor-se, torna-se uma grande tendência e triunfa, o que se aplica à história das idéias... ( Morin, 2003, p. 20).

Prevê-se, portanto, a emergência de uma outra forma de ciência que ocorre como resíduo daquela certeza que só se define ao determinar e reduzir o conhecimento.
Enquanto resíduo de certezas temporais e espaciais, o tempo real e a realidade integral como nomes metafóricos do ciber-espaço e da cultura que lhe é conseqüente resgatariam, portanto, fragmentos de uma epistemologia da comunicação que ainda comunga da necessidade daquela segurança funcional que decorria do caráter instrumental dos meios técnicos que, aplicados, lhe garantia espaço social e cultural.

Porém, na indiferenciação ou indeterminação daquele objeto científico que se insiste em traduzir de modo eufórico ou disfórico, é possível apreender não o conteúdo que possa ordená-lo ou classificá-lo, mas similitudes que, movediças e instáveis, podem sugerir ao conhecimento estabelecido pela tradição, outras identidades que, mais complexas são, por assim dizer, pós-epistemológicas, na medida em que apontam para a urgente necessidade de revisão daquela epistemologia funcional dos meios da comunicação de massa que constitui a base de um conhecimento já credenciado. Nesse sentido, Flusser é decisivo:

[...] o reconhecimento do intelecto não é um instrumento para dominar o caos, mas é um canto de louvor ao nunca dominável. O nome próprio não é o resultado de um esforço intelectual, mas de um choque entre o intelecto e o indominável. O nome próprio é a síntese do intelecto com o de tudo diferente (Flusser, 1999, p. 74).

Entretanto, o ciberespaço e suas conseqüências culturais se afastam de modo acelerado daquilo que foi rotulado pelos antigos meios e superando a linearidade de um efeito comunicativo, busca-se a circularidade das consequências imprevisíveis ou díspares, porque decorrem da indeterminada característica de meios comunicativos que, ambientalmente, contagiam o planeta , mas resistem à sua determinação e controle.

Até agora ,não se pode saber o que ée, sobretudo, o que fazer com o conhecimento ciber, embora sejam produzidos unívocos discursos que, descritivos ou constativos, procuram operacionalizar hipóteses para as conseqüências que deverão agitar o mundo dominado pela tecnologia ou desenhar o presente com recursos que utilizam imprevistas interatividades ou subjetividades híbridas, imersivas ou móveis.

Ante um objeto científico que, indeterminado, não se esvazia de sentido, é necessário produzir o conhecimento que, imaginário e sem nome, silenciosamente abdica da necessidade de tudo explicar.

Ante esse estranho objeto, urge admitir que as consequências da tecnologia digital entendidas como espaço e cultura colocam para a epistemologia da comunicação um desafio ímpar que impõe a revisão das suas certezas teóricas e empíricas mamecos

\section{NOTA}

* Este texto foi apresentado no II Simpósio Nacional 
da ABCiber realizado em novembro de 2008

\section{REFERÊNCIAS}

BAUDRILLARD, Jean . El Pacto de Lucidez o la Inteligencia del Mal. Buenos Aires: Amorrortu, 2008.

. A Ilusão Vital. Rio de Janeiro: Civilização Brasileira, 2001.

BAUMAN, Zygmunt. Modernidade e Ambivalência. Rio de Janeiro: Jorge Zahar, 1999.

BORGES, Jorge Luis. Ficciones. Buenos Aires: Emecé, 1956.

DERRIDA, Jacques. L'Ecriture et la Différence. Partis: Seuil, 1967.

FLUSSER, Villén. A Dúvida. Rio de Jareiro: Relume Dumará, 1999.

FOUCAULT, Michel. As Palavras e as Coisas. São Paulo: Martins Fontes, 1987 ( 4.ed).

GATES, Bill. A Estrada do Futuro. São Paulo: Companhia das Letras, 1996.

HILLIS, Ken. Sensações Digitais. Rio dos Sinos: Unisinos, 2003.

HERÁCLITO DE ÉFESO. Sobre a Natureza. In: COLLINSON, Diane. 50 Grandes Filósofos da Grécia Antiga ao Século XX. São Paulo: Contexto, 2004.

KUHN, Thomas. Estrutura das Revoluções Científicas. São Paulo: Perspectiva, 1978.

. O Caminho desde a Estrutura. São Paulo: Edunesp, 2006.

KERKHOVE, Derrick de. A Pele da Cultura Uma investigação sobre a nova realidade eletrônica. Lisboa: Relógio D’agua, 1997.

LEVY, Pierre. As Tecnologias da Inteligência. Rio de Janeiro, ed. 34.1993.

_. O que évirtual. São Paulo, ed. 34, 1996.

_. Cibercultura. São Paulo: Ed. 34, 1999.

LOTMAN, Iuri . La Semiosfera 3 vols ( trad. Desiderio Navarro). Valência: Frónesis, 2000.

MAFFESOLI, Michel. Elogio da Razão Sensível. Petrópolis: Vozes, 2005.

MANOVICH, Lev. El Lenguage de los Nuevos Medios de Comunicación: la imagen en la era digital. Buenos aires:
Paidós, 2006

MORIN, Edgar. Da necessidade de um pensamento complexo. In: MENEZES, Francisco; SILVA, Juremir Machado. Para Navegar no Século XXI Tecnologias do Imaginário e Cibercultura (Orgs.) 3. ed. Porto Alegre: Sulina/Edpucrs, 2003.

NEGROPONTE, Nicholas. A Vida Digital. São Paulo: Companhia das Letras, 1995.

RHEINGOLD, Howard. A Comunidade Virtual. Lisboa: Gradiva, 1996.

ROSSI, Paolo. A Ciência e a Filosofia dos Modernos. São Paulo: Edunesp, 1992.

TAPIAS, José Antonio. Internautas e Náufragos: A busca de sentido na cultura digital. São Paulo: Loyola, 2006.

TRIVINHO, Eugênio. A Dromocracia Cibercultural. São Paulo: Paulus, 2007.

VIRILIO, Paul.O Espaço Crítico. Rio de Janeiro: Ed. 34, 1993.

—. A Arte do Motor. São Paulo: Estação das Letras, 1996.

_. Cibermundo a política do pior. Lisboa: Teorema, 2000.

_. Estratégia da Decepção. São Paulo: Estação Liberdade. 2000 .

_. A Máquina de Visão. Rio de Janeiro: José Olympio, 2002.

_. L'Accident Originel. Paris: Galilée, 2005. 